\title{
Modos e formas de apropriação da escola pelas comunidades remanescentes de
}

\author{
quilombo: alguns apontamentos
}

\section{Types and ways of school appropriation by quilombo remaining communities: some points}

Viviane da Silva Araújo Vitor ${ }^{1}$

José Valdir Jesus de Santana ${ }^{2}$

\begin{abstract}
Resumo: Neste artigo, nosso objetivo é apresentar uma diversidade de experiências sobre a educação escolar quilombola, no sentido de problematizar em que medida essas experiências têm se constituído em conformidade com o que determinam as Diretrizes Curriculares Nacionais para a Educação Escolar Quilombola, instituídas em 2012. Nosso objetivo é,também, tensionar em que medida as experiências de educação escolar quilombola que, segundo a normativa, devem se constituir a partir de princípios como diferença e especificidade,têm sido elaboradas tendo como referência a interculturalidade crítica. Trata-se, portanto, de um levantamento de pesquisas realizadas em diferentes regiões do país que buscam compreender os modos e formas de apropriação da escola por parte das comunidades remanescentes quilombolas, com destaque para as realizadas no estado da Bahia. Nas pesquisasaqui analisadas, muitas das escolas, inclusive em territórios quilombolas, estão prenhes de práticas epistemicidas, racistas e monoculturais, posto que continuam estruturadas pela lógica da colonialidade Contudo, os coletivos negros e quilombolas estão empenhados na produção de "ecologias dos saberes" (SANTOS, 2006), sejam nos espaços escolares ou fora dele, mesmoa despeito das muitas dificuldades que enfrentam e, nesse sentido, a escola tem ocupado um lugar importante no fortalecimento das lutas e demandas que se colocam contemporaneamente,na reelaboração das identidades desses coletivos e na valorização de suas tradições.
\end{abstract}

Palavras-chave: Comunidades remanescentes de quilombo. Educação escolar quilombola. Interculturalidade crítica.

Abstract: In this article, our objective is to present a diversity of experiences on Quilombola school education, to problematize the extent to which these experiences have been constituted in accordance with what the National Curriculum Guidelines for Quilombola School Education, established in 2012. Our objective is also to tense to what extent the Quilombola school

\footnotetext{
${ }^{1}$ Graduação em Pedagogia pela Universidade do Estado da Bahia - UNEB; mestranda pelo Programa de PósGraduação em Ensino pela Universidade Estadual do Sudoeste da Bahia - UESB. Professora da Educação Básica do município de Brumado/BA. E-mail: viviaraujo_gbi@hotmail.com Orcid: https://orcid.org/0000-0003-15527502

${ }^{2}$ Doutorado em Antropologia Social pela Universidade Federal de São Carlos - UFSCar. Professor titular da Universidade Estadual do Sudoeste da Bahia - UESB. E-mail: jsantana@uesb.edu.br Orcid: https://orcid.org/0000-0001-7215-2562
}

Sertanias: Revista de Ciências Humanas e Sociais - ISSN: 2763-566X Volume 1, número 1, julho-dezembro de 2020. 
education experiences that, according to the norms, should be constituted from principles such as difference and specificity, have been elaborated concerning critical interculturality. It is, therefore, a survey of research carried out in different regions of the country that try to understand the ways and forms of appropriation of the school by the remaining quilombola communities, with emphasis on those carried out in the state of Bahia. In the research analyzed here, many schools, including in quilombola territories, are crossed by epistemic, racist, and monocultural practices, since they continue to be structured by the logic of coloniality. However, black and quilombola collectives are committed to the production of "knowledge ecologies" (SANTOS, 2006), whether in school spaces or outside of it, even despite the many difficulties they face and, in this sense, the school has played an important role in strengthening the struggles and demands that arise today, in the re-elaboration of the identities of these collectives and in valuing their traditions.

Keywords: Remaining quilombo communities. Quilombola school education. Critical interculturality.

\section{Introdução}

A luta pelo direito à inserção dos povos tradicionais ${ }^{3}$ no sistema formal de ensino é também um processo que reescreve a história dos negros no cenário nacional, a partir das narrativas de espaço-tempo delineados pelas políticas de negação e falta de reconhecimento por parte do estado. Acionar a discussão sobre a educação escolar quilombola, é na verdade, uma maneira de fomentar as reivindicações históricas dos movimentos sociais negros e principalmente compreender que ambas estão conectadas à realidade política, social e econômica do sistema-mundo civilizado. Por mais que nossa pesquisa tenha como foco um contexto escolar que não se "apresenta como quilombola", posto tratar-se de uma instituição que não foi pensada para e com a comunidade remanescente de quilombo em questão, objetivamos, neste artigo, em um primeiro momento, mesmo que de forma breve, recuperar como se constituiu o debate e a caracterização de projetos de educação pensados com e para as comunidades remanescentes de quilombo, na medida em que acreditamos, também inspirados em Gomes (2012), que a educação ofertada a estudantes de comunidades quilombolas que

\footnotetext{
${ }^{3}$ Em 2007, o governo brasileiro através do Decreto $n^{\circ}$ 6040/07 reconhece a existência de distintos povos e comunidades tradicionais (PCT) na sociedade. "Povos e Comunidades Tradicionais: grupos culturalmente diferenciados e que se reconhecem como tais, que possuem formas próprias de organização social, que ocupam e usam territórios e recursos naturais como condição para sua reprodução cultural, social, religiosa, ancestral e econômica, utilizando conhecimentos, inovações e práticas gerados e transmitidos pela tradição” (BRASIL, 2007).
}

\section{Sertanias: Revista de Ciências Humanas e Sociais - ISSN: 2763-566X Volume 1, número 1, julho-dezembro de 2020.}


adentram às escolas não quilombolas deve se constituir a partir dos princípios que orientam a educação escolar quilombola. Nesses termos, toda e qualquer instituição escolar que atenda a estudantes pertencentes a esses coletivos não pode perder de vista este princípio, posto que conforme as referidas Diretrizes a "Educação Escolar Quilombola é a modalidade de educação que compreende as escolas quilombolas e as escolas que atendem estudantes oriundos de territórios quilombolas" (BRASIL, 2012, p. 27).

Nosso objetivo é, também, tensionar em que medida as experiências de educação escolar quilombola que, segundo a normativa, devem se constituir a partir de princípios como diferença e especificidade, têm sido elaboradas tendo como referência a interculturalidade crítica que, conforme Candau (2003, p. 32), deve orientar "processos que têm por base o reconhecimento do direito à diferença e a luta contra todas as formas de discriminação e desigualdade social", de forma a favorecer "os processos de negociação cultural, a construção de identidades de "fronteira", "híbridas", plurais e dinâmicas, nas diferentes dimensões da dinâmica social" (p.35).

Ressaltamos que as reflexões apresentadas neste artigo resultam da pesquisa de mestrando que estamos realizando junto ao Programa de Pós-Graduação em Ensino da Universidade Estadual do Sudoeste da Bahia.

\section{A modalidade de educação escolar quilombola: breves considerações}

O debate em torno da educação formal para as populações negras em nosso país ainda é considerado muito recente, tendo em vista que o Brasil nutre profundas raízes escravocratas na construção da sua sociedade, devido aos longos anos de exploração dos negros que eram trazidos para cá na condição de escravizados. Muitos desses povos foram arrancados de seus territórios, em África, e submetidos a condições degradantes de violência, em que se buscou despi-los de suas identidades, de seus costumes, para viverem as imposições do colonialismo europeu que habitava o solo brasileiro à época e, em nome da "ordem econômica e social" tiveram negado o direito de acesso à escola formal.

Deixar de ser um "ex-escravo" ou liberto para ser um cidadão, ter direitos iguais, não ser visto como inferior e vivenciar a cidadania plena era um sonho perseguido pela população negra da época sobretudo os setores mais organizados. Entre suas reivindicações, a educação se tornou prioritária, pois o analfabetismo e a lenta inserção nas escolas oficiais se constituíram um dos

\footnotetext{
Sertanias: Revista de Ciências Humanas e Sociais - ISSN: 2763-566X Volume 1, número 1, julho-dezembro de 2020.
} 
principais problemas dessa população para a inserção no mundo do trabalho (GOMES, 2017, p. 29).

Os saberes culturais dos grupos escravizados eram os mais variados, pois estes advinham de diversas partes do continente africano e representavam, portanto, uma diversidade de culturas e grupos étnicos. A condição de alijados da sociedade, alinhada aos critérios cognitivos de opressão, alimentavam a normativa de manter a população negra sobre o domínio da escravidão, "pois realmente a manifestação cultural de origem africana, na integridade de seus valores, na dignidade de suas formas de expressões, nunca tiveram reconhecimento no Brasil” (NASCIMENTO, 2016, p. 112-113).

Assim, a aceitação do povo negro como categoria política e epistêmica exigia o seu reconhecimento por parte do Estado brasileiro, o que só aconteceria a partir das lutas e reivindicações dos movimentos sociais insurgentes que se expressarão na Constituição Federal de 1988. Estes que transgrediram os sistemas de invisibilidades e condicionaram a voz subalterna a outras esferas, podemos dizer que a formação dos quilombos é sem dúvida um exemplo significativo desse processo de insubmissão e transgressão, para inserir e recolocar o negro em um novo campo político. Como afirma Gomes (2017), o movimento negro, entendido como sujeito político produtor e produto das experiências sociais diversas, atua para a ressignificação da questão étnico-racial e firma-se como um sujeito de conhecimento na formulação da nossa história.

As contestações em defesa da educação escolar quilombola nascem na década de 1980, no intuito de ressignificar a função social da escola para as comunidades de quilombo. Os movimentos sociais passam a revelar o preconceito e a discriminação no interior da educação pública e, nesse sentido, a partir do "tensionamento do Movimento Negro é possível entender a criação das Diretrizes Curriculares Nacionais para a Educação Escolar Quilombola no ano de 2012, durante o governo da presidente Dilma Rousseff (CAMPOS; GALLINARI, 2017, p. 217).

Desse modo, a conquista da educação escolar quilombola no campo normativo da educação no Brasil, perpassa pelas ações afirmativas conquistadas pelo movimento negro como sujeito político, que traz o debate sobre a dívida do estado para com os povos historicamente marginalizados. É substancial destacarmos que as discussões em torno da necessidade de políticas de ações afirmativas para a educação escolar quilombola estão assentadas na lei

\footnotetext{
Sertanias: Revista de Ciências Humanas e Sociais - ISSN: 2763-566X Volume 1, número 1, julho-dezembro de 2020.
} 
10.639/03, quando altera a Lei de Diretrizes e Bases da Educação Nacional de 1996, quando determina a obrigatoriedade do ensino da História e Cultura Afro-brasileira e Africana e insere os conteúdos acerca da História da África e dos africanos, assim como, a luta dos negros no Brasil, sua cultura e atuação na formação da sociedade brasileira, que devem ser abordadas nas escolas de ensino fundamental e médio (BRASIL, 2003).

A referida lei foi regulamentada pelo Conselho Nacional de Educação, respectivamente, por meio do Parecer CNE/ CP 3/2004, bem como pela Resolução CNE/CP 01/2004 que tratam das Diretrizes Curriculares Nacionais - DCNs para Educação das Relações Étnico-Raciais e para o Ensino da cultura Afro-Brasileira, onde acentuam as primeiras proposições para o ensino da história dos quilombos.

A Conferência Nacional de Educação - CONAE realizada em Brasília no ano de 2001, realizou debates importantes sobre os diretos quilombolas, e nessa direção, promove a educação escolar quilombola como uma modalidade de Educação Básica no parecer 07/2010 do Concelho Nacional de Educação/Câmera de Educação Básica - CNE/CEB e ainda, na resolução04/2010, que trazem as Diretrizes Curriculares Gerais para a educação básica no Brasil. E já naCONAE realizada em março de 2010, justifica-se a necessidade de definir uma política pública educacional que assuma a centralidade dos anseios das comunidades quilombolas, "portanto, não cabe mais considerar a educação quilombola como uma modalidade intitulada educação do campo, é preciso levar em conta as especificidades culturais e históricas dessas comunidades" (MACÊDO, 2015, p.92).

Em novembro de 2010 realizou-se em Brasília o I Seminário Nacional de Educação Quilombola, organizado pelo Ministério da Educação (MEC), por meio da Secretaria de Educação Continuada, Alfabetização, Diversidade (SECAD), com apoio da Secretaria de Políticas de Promoção da Igualdade Racial (SEPPIR), do Instituto Nacional de Colonização e Reforma Agrária (INCRA) e da Coordenação Nacional de Articulação das Comunidades Negras Rurais Quilombolas (CONAQ). O evento contou com 240 pessoas, entre as quais lideranças quilombolas, gestores/as das Secretarias Municipais e Estaduais de Educação, gestores/as e professores/as de escolas situadas nas comunidades quilombolas, professores/as e pesquisadores/as da educação para as relações étnico-raciais (MACÊDO, 2015, p. 92).

A partir do seminário citado pela autora, foi designada a comissão de acompanhamento da elaboração das Diretrizes Curriculares Nacionais para a Educação Escolar Quilombola, que contou com a participação de diversas lideranças quilombolas, pesquisadores e representantes

\footnotetext{
Sertanias: Revista de Ciências Humanas e Sociais - ISSN: 2763-566X Volume 1, número 1, julho-dezembro de 2020.
} 
de instituições ligadas aos estudos e comunidades quilombolas. Diante disso, no ano de 2011, foram realizadas três audiências públicas para fomentar a elaboração das Diretrizes Curriculares Nacionais - DCNs para a Educação escolar Quilombola, realizadas estado da Bahia, Maranhão e Brasília.

As três audiências públicas tiveram como tema: "A Educação Escolar Quilombola que temos e a que queremos" e contaram com a participação de quilombolas e de suas lideranças, dos movimentos sociais, das organizações não governamentais (ONGs), fóruns estaduais e municipais de educação e diversidade étnico-racial, gestores/as públicos, pesquisadores/as, professores/as, estudantes e demais interessados no tema (MACÊDO, 2015, p. 94).

Desse modo, em 05 de junho de 2012 foi aprovado o parecer CNE/CEB 16/2012, que versa sobre as Diretrizes Nacionais para a Educação Escolar Quilombola, que através da resolução 08/2012 estabelece as orientações curriculares para que os sistemas de ensino possam implementar e regulamentar a Educação Escolar Quilombola no âmbito da educação básica em nível nacional, onde destaca os seguintes princípios:

Art. $7^{\circ}$ A Educação Escolar Quilombola rege-se nas suas práticas e ações político- pedagógicas pelos seguintes princípios:

I - direito à igualdade, liberdade, diversidade e pluralidade;

II - direito à educação pública, gratuita e de qualidade;

III - respeito e reconhecimento da história e da cultura afro-brasileira como elementos estruturantes do processo civilizatório nacional; IV - proteção das manifestações da cultura afro-brasileira; V valorização da diversidade étnico-racial;

VI - promoção do bem de todos, sem preconceitos de origem, raça, sexo, cor, credo, idade e quaisquer outras formas de discriminação;

VII - garantia dos direitos humanos, econômicos, sociais, culturais, ambientais e do controle social das comunidades quilombolas; VIII reconhecimento dos quilombolas como povos ou comunidades tradicionais;

XIX - conhecimento dos processos históricos de luta pela regularização dos territórios tradicionais dos povos quilombolas;

$\mathrm{X}$ - direito ao etnodesenvolvimento entendido como modelo de desenvolvimento alternativo que considera a participação das comunidades quilombolas, as suas tradições locais, o seu ponto de vista ecológico, a sustentabilidade e as suas formas de produção do trabalho e de vida;

XI - superação do racismo - institucional, ambiental, alimentar, entre outros - e a eliminação de toda e qualquer forma de preconceito e

\section{Sertanias: Revista de Ciências Humanas e Sociais - ISSN: 2763-566X Volume 1, número 1, julho-dezembro de 2020.}


discriminação racial; XII - respeito à diversidade religiosa, ambiental e sexual;

XV - superação de toda e qualquer prática de sexismo, machismo, homofobia, lesbofobia e transfobia;

XVI - reconhecimento e respeito da história dos quilombos, dos espaços e dos tempos nos quais as crianças, adolescentes, jovens, adultos e idosos quilombolas aprendem e se educam;

XVII - direito dos estudantes, dos profissionais da educação e da comunidade de se apropriarem dos conhecimentos tradicionais e das formas de produção das comunidades quilombolas de modo a contribuir para o seu reconhecimento, valorização e continuidade;

XVIII - trabalho como princípio educativo das ações didáticopedagógicas da escola;

XIX - valorização das ações de cooperação e de solidariedade presentes na história das comunidades quilombolas, a fim de contribuir para o fortalecimento das redes de colaboração solidária por elas construídas; XX - reconhecimento do lugar social, cultural, político, econômico, educativo e ecológico ocupado pelas mulheres no processo histórico de organização das comunidades quilombolas e construção de práticas educativas que visem à superação de todas as formas de violência racial e de gênero.

Nilma Lino Gomes (2012), relatora do parecer sobre as Diretrizes Curriculares Nacionais para a Educação Escolar Quilombola, recoloca o protagonismo das comunidades quilombolas ao longo de nossa história e, nesse sentido, os sujeitos quilombolas são compreendidos como atores políticos que forjam nas lutas suas demandas, ao mesmo tempo em que denunciam todas as formas de desigualdades e preconceitos que recaem sobre essas comunidades. Nesse sentido, "esse histórico de lutas tem o Movimento Quilombola e o Movimento Negro como os principais protagonistas políticos que organizam as demandas das diversas comunidades quilombolas de todo o país e as colocam nas cenas pública e política, transformando-as em questões sociais" (GOMES, 2012, p. 13). Ademais, conforme Gomes,

Considerando-se o processo histórico de configuração dos quilombos no Brasil e a realidade vivida, hoje, pelas comunidades quilombolas, é possível afirmar que a história dessa parcela da população tem sido construída por meio de várias e distintas estratégias de luta, a saber: contra o racismo, pela terra e território, pela vida, pelo respeito à diversidade sociocultural, pela garantia do direito à cidadania, pelo desenvolvimento de políticas públicas que reconheçam, reparem e garantam o direito das comunidades quilombolas à saúde, à moradia, ao trabalho e à educação (GOMES, 2012, p. 12).

Sertanias: Revista de Ciências Humanas e Sociais - ISSN: 2763-566X Volume 1, número 1, julho-dezembro de 2020. 


\section{Situando algumas pesquisas sobre a educação escolar quilombola}

Para Gomes (2017, p. 36) "é possível perceber que o estado brasileiro, ao reconhecer a imbricação entre desigualdades e diversidade, vem incorporando, aos poucos, a raça de forma ressignificada em algumas de suas ações políticas, especialmente na educação". Assim, o cenário epistemológico brasileiro, através da promoção da diversidade e a busca por igualdade, empreende um novo rumo enunciativo às práticas e discursos sob o locus da perspectiva negra. Nesse viés, pontuamos algumas produções teóricas/acadêmicas que apresentam estudos relacionados a educação escolar quilombola e a educação quilombola, que nos auxiliam a compreender os distintos modos de apropriação da escola por parte desses coletivos negros, as tensões e dificuldades que se colocam para a construção de projetos de escola pautados nos princípios da diferença, especificidade e interculturalidade; a crítica epistêmica que muitos desses projetos e experiências tem realizado frente à concepções eurocêntrica de conhecimento, currículo e educação.

A educação quilombola acontece no seio das comunidades quilombolas, por meio das relações estabelecidas entre os sujeitos, que imprimem modos de produção e de transmissão de conhecimentos que são valorizados por esses coletivos. Já a educação escolar quilombola incide em uma aproximação entre os saberes da comunidade e os conhecimentos curriculares desenvolvidos na escola. Desse modo, "Educação Escolar Quilombola é a modalidade de educação que compreende as escolas quilombolas e as escolas que atendem estudantes oriundos de territórios quilombolas" (BRASIL, 2012, p. 27). Portanto, entende-se por escola quilombola aquela localizada em território quilombola.

Sobre a emergência dos processos de reparação ao silenciamento das comunidades negras no Brasil, que deram origem a modalidade de educação escolar quilombola, Santana, Eugênio, Oliveira e Pereira (2016) fazem uma análise das pesquisas sobre educação escolar quilombola, publicadas pela Associação Nacional de Pós-Graduação e Pesquisa em Educação - ANPED, no Grupo de Trabalho intitulado Educação e Relações Étnico-raciais- GT 21. Foram consultados os trabalhos publicados na forma de comunicação oral entre os anos de 2002 a 2015, com o propósito de compreender os modos e formas de apropriação da escola por parte das comunidades remanescentes de quilombos, de acordo com a definição da Constituição Federal de 1988, e ainda ressaltam a interface com a antropologia e educação.

\footnotetext{
Sertanias: Revista de Ciências Humanas e Sociais - ISSN: 2763-566X Volume 1, número 1, julho-dezembro de 2020.
} 
Criado oficialmente na $24^{\mathrm{a}}$ Reunião Anual da Associação, em 2001, com o nome Grupo de Estudos Afro-Brasileiros e Educação, a partir de 2009, tornase Grupo de Trabalho sobre Educação e Relações Étnico-raciais; este GT têm sido um espaço de discussão importante em torno das questões étnico-raciais e de sua articulação com o campo da educação e da educação escolar. Analisamos os trabalhos publicados na forma de comunicação oral entre os anos de 2002 a 20153. Neste período, foram publicados 165 trabalhos na forma de comunicação oral; destes, somente 13 tinham como "objeto" de estudo comunidades quilombolas, sendo que 12 estavam relacionados à educação escolar quilombola (SANTANA; EUGÊNIO; OLIVEIRA; PEREIRA 2016, p. 143).

Em uma breve apresentação das pesquisas nesse cenário, os autores identificam que, mesmo sendo um campo em configuração, os estudos que propõem analisar as questões da educação e da educação escolar quilombola têm avançado. No entanto, Santana, Eugênio, Oliveira e Pereira (2016) entendem que a educação escolar quilombola atende a realidades distintas às comunidade quilombolas, o que implica que devemos atentar para como cada comunidade tem construído seus projetos de escola, ou seja, aquilo que os mobilizam enquanto comunidade quilombola, suas especificidades e alternâncias. Por isso, trata-se de atender cada comunidade dentro de um plano de diversidade que envolve os mais variados modos de existência e enfretamentos desses povos no território brasileiro.

De certo modo, as pesquisas aqui apresentadas permitem afirmar que esta modalidade de educação tem sido construída de forma bastante variada e, por vezes, controversa. Maroun e Arruti (2010, 2011), por exemplo, apresentaram os conflitos, dificuldades e disputas envolvidos na construção das escolas quilombolas no Rio de Janeiro: conflitos entre o modelo de escola rural pensado para as comunidades quilombolas, pelas secretarias de educação, que se chocam com o modelo de escola que os quilombolas pensam e desejam para si. Por outro lado, esses mesmos autores demonstram como essas tensõestêm produzido, por parte dos quilombolas, um movimento em terno de uma escola diferenciada e na construção de uma "pedagogia quilombola". Apesquisa de Miranda (2011) refletiu acerca das condições de precariedade das escolas quilombolas de Minas Gerais, tanto no que diz respeito à construção das políticas de educação voltadas para essas comunidades, quanto no que concerne às políticas de formação de professor e a qualidade da educação ofertada. Silva (2011), por outro lado, tendo como campo de pesquisa a Comunidade Quilombola Conceição dos Crioulos, em Pernambuco, demonstra como a escola tem sido construída a partir de um projeto de comunidade, numa perspectiva diferenciada e, nesse sentido, a escola está a serviço da comunidade. Recuperamos esses exemplos para mostrarmos a variedade de projetos de escola que estão a se formar por todo o Brasil, em alguns casos com certo pessimismo, sobretudo por parte dos pesquisadores (SANTANA; EUGÊNIO; OLIVEIRA; PEREIRA 2016, p. 152 e 153).

\section{Sertanias: Revista de Ciências Humanas e Sociais - ISSN: 2763-566X Volume 1, número 1, julho-dezembro de 2020.}


É sabido, como destacam Macedo (2019) e Gusmão e Souza (2012) que em muitas das comunidades quilombolas de nosso país a educação escolar não tem sabido dialogar com os conhecimentos elaborados por esses coletivos, portanto, com suas práticas educativas, o que tem dificultado a construção de experiências de educação escolar pautadas no que definem as Diretrizes Curriculares Nacionais para a Educação Escolar Quilombola.

Com uma proposta semelhante a de Santana (et al, 2016), Macedo e Santos (2018) apresentam um estado da arte, onde buscaram identificar Teses e Dissertações de programas de Pós-Graduação em Educação do país, que abordassem a Educação Escolar Quilombola em instituições formais de ensino, nesse caso escolas de ensino básico. Os autores verificaram 23 trabalhos, de diferentes regiões do país e, após análise, constataram que somente 5 trabalhos faziam referência às Diretrizes Curriculares Nacionais para a Educação Escolar Quilombola na Educação Básica, legislação vigente desde 2012 e que regulamenta essa modalidade de ensino. Desse modo, concluem que do total de 23 trabalhos, somente 4 apresentaram resultados que consideravam positivos.

Sobre os resultados, das 23 pesquisas, somente 4 apresentaram resultados que podemos considerar positivos. Esses resultados podem ser sintetizados na importância da escola dentro das comunidades. Identificamos que a escola quilombola se mostrou como elemento importante na articulação e fortalecimento das suas lutas e resistência assim como da sua identidade. A escola também se mostrou como fator essencial para desenvolvimento social da comunidade. Já em relação aos alunos uma das pesquisas mostrou que as crianças, alunos e alunas, têm saberes característicos do grupo de pertença, necessário para efetivação da educação quilombola (MACEDO; SANTOS 2018, p. 14).

Gusmão (2020) apresenta uma leitura contemporânea de como as pesquisas têm refletido sobre a educação quilombola nos processos educativos que se inter-relacionam com a proposta oficial da educação quilombola e os seus desdobramentos em diferentes contextos. Para tal, a autora parte das perguntas: como tais processos ocorrem? O que revelam em termos de etnicidade e mediação? E, afim de respondê-las, aciona alguns pontos de interação entre a antropologia e educação, que auxiliam na reflexão das diversidades culturais e sociais que perpassam as ações educativas escolarizadas ou não, tendo como foco duas comunidades quilombolas, uma localizada no estado de São Paulo e a outra no Rio de Janeiro. Sertanias: Revista de Ciências Humanas e Sociais - ISSN: 2763-566X
Volume 1, número 1, julho-dezembro de 2020. 
Para tanto, busca-se evidenciar alguns elementos que se apresentam no conjunto das relações vividas por duas comunidades quilombolas, uma no estado de São Paulo e, outra no estado do Rio de Janeiro, a título de exemplos da luta por educação específica e diferenciada, ou seja, a luta por uma educação quilombola. Pretende-se considerar em tais contextos, a questão da etnicidade e da mediação para evidenciar as experiências vividas que se revelam como aprendizagens em contextos de mudanças sociais e políticas que se fazem necessárias no campo da luta (GUSMÂO, 2020 p. 11).

Trata-se, em sua análise, do Quilombo Brotas, situado no município de Itatiba/SP, que é formado por 170 pessoas, e Campinho da Independência, que faz parte do município de Paraty, localizado ao sul do estado do Rio de Janeiro. A autora aciona conceitos como etnicidade e mediação "[...] para evidenciar as experiências vividas que se revelam como aprendizagens em contextos de mudanças sociais e políticas que se fazem necessárias no campo da luta pela terra e por direitos específicos" (GUSMÂO, 2020, p. 9).

Sobre o Quilombo Brotas, a autora relata a história da luta pelas terras que foram compradas por escravos alforriados, como garantia de uma vida mais justa para os que viriam, no futuro, fazer parte daquele território, algo que tem mobilizado o grupo até os dias atuais, e o que alimenta o sentido de uma vida em comunidade e conduz a luta do grupo em defesa da terra e, para isso, esses sujeitos acionam a ancestralidade e a resistência, em uma sociedade marcada pela desigualdade.

“O campo político e identitário do grupo na relação com a sociedade envolvente, irá caracterizar o grupo e suas terras como pertencentes a um quilombo urbano" (GUSMÂO, 2020, p. 12). A autora ressalta que, ao movimentar os saberes sociais em torno da luta pela terra, o Quilombo Brotas realiza “[...] um processo educativo de caráter mais geral que a educação escolar e que abrange a todos, crianças, jovens, adultos e velhos" (GUSMÂO, 2020, p. 12). Posto isso, afirma que atuam como agentes mediadores, entre o grupo e o estado, uma vez que os seus direitos reverberam no contexto político de ensino aprendizagem e envolve os diferentes sujeitos.

Nesse contexto em que não apenas aprendem o que até então não conheciam, mas aprendem, também, com outros processos, formas de interpretar o passado grupal de compra da terra pelos antepassados como garantia de seus direitos e, com os quais buscam compreender o presente da luta e as perspectivas do futuro. É assim, que a memória dos mais antigos, da compra da terra e dos laços de parentesco confirmam o lugar e dizem deles, daquilo que são enquanto negros, parentes e herdeiros de Isaac e Amélia[...] (GUSMÃO, 2020, p. 13).

\section{Sertanias: Revista de Ciências Humanas e Sociais - ISSN: 2763-566X Volume 1, número 1, julho-dezembro de 2020.}


O quilombo de Campinho da Independência se organiza em torno da luta pela terra. Um contexto conflituoso, já que não possui a documentação legal que comprove que são os donos das terras. "A história da comunidade, centrada na oralidade e na comunicação dos mais velhos com as gerações mais novas, se fazia em meio a fragmentos de memória que diziam de ali estarem, desde muito tempo" (GUSMÃO, 2020, p. 14).

Os relatos a respeito de duas comunidades - Brotas/SP e Campinho da Independência/RJ - através da história de suas lutas trazem à tona o que é educação e como ela se realiza nas relações entre sujeitos iguais e diferentes por meio de um contexto de encontros, desencontros, trocas e aprendizagens. A educação como um universo pautado pela mediação compreendida como espaço de relações, pressupõe o debate em torno da educação para diversidade e impõe a reflexão sobre cultura e cidadania, dois aspectos fundamentais na formação dos sujeitos sociais, de sua realidade social e política (GUSMÃO, 2020, p.20).

Ademais, segundo Gusmão,

A luta do povo negro por educação e superação do preconceito, mostra que a escola é ainda um valor para esses grupos, mas que, por sua natureza é ela ainda propagadora do preconceito e do racismo que precisam ser superados para dar lugar a políticas públicas e sociais que possam reconhecer a diversidade étnica-cultural dos diferentes grupos. Assim, os chamados "quilombos contemporâneos", as comunidades negras de agora, encontram na educação, nas aprendizagens na escola e fora dela, o valor das leis que regulamentam reconhecimento e direitos. Abre-se um novo universo de luta e de ações que ensejam políticas públicas diversas e que colocam em movimento as mediações societárias e culturais entre eles e outros atores, na conquista da cidadania e de direitos, tendo em conta o pertencimento étnico, o direito à terra e outros direitos (2020, p. 24).

A pesquisa de Souza (2018) buscou compreender os programas e as ações do poder público municipal destinados à Comunidade dos Arturos, que se localiza no bairro Jardim Vera Cruz, em Contagem, no estado de Minas Gerais, com o intuito de identificar aspectos relacionados à gestão social e ao desenvolvimento local.

Partindo do pressuposto de que a educação é o fio condutor para emancipação de sujeitos enquanto atores sociais no exercício de ações para a transformação de sua realidade local, acredita-se que a escola é um espaço potencial de discussão e participação. Por isso, esta pesquisa apresentou como produto técnico a proposta de um fórum para se discutirem informações a respeito das práticas pedagógicasrelacionadas às Diretrizes Curriculares Nacionais para a Educação Escolar Quilombola, a ser realizado na escola que atende à maioria dosalunos da Comunidade dos Arturos (SOUZA, 2018, p. 119).

\section{Sertanias: Revista de Ciências Humanas e Sociais - ISSN: 2763-566X Volume 1, número 1, julho-dezembro de 2020.}


Franco (2018) analisou a efetivação das Diretrizes Curriculares Nacionais para a Educação Quilombola na Comunidade Remanescente de Quilombo São Domingos, no município de Paracatu, Minas Gerais. Ao analisar a educação quilombola na referida Comunidade, apontou como principal objetivo compreender como as políticas públicas para esta modalidade de educação se materializam nesta comunidade. A autora destaca que os resultados apontam as lacunas entre o consenso jurídico em torno das questões raciais e a materialização das conquistas na prática, diagnosticou algumas contradições envolvidas no processo de construção da identidade quilombola, na educação e no autoconhecimento da comunidade. Contudo, faz apontamentos à resistência quilombola na luta por seus direitos à escolarização, terras, sobrevivência e por um futuro melhor, trazendo evidências da importância da oralidade, da cultura e da ancestralidade no âmbito da organização comunitária, como também alguns vácuos deixados pela ausência da educação escolar e os silenciamentos da cultura quilombola nos currículos das escolas que atendem estudantes da comunidade, mesmo diante dos avanços das construções propostas nos dispositivos legais.

Rodrigues (2017) buscou compreender como tem sido pensada e executada a educação na Escola Municipal Prefeito Joaquim Ribeiro de Paula, localizada na Colônia do Paiol, e sua relação com a comunidade entre os anos de 2015 e 2016, sob os pressupostos das políticas públicas voltadas para as comunidades quilombolas, principalmente para a educação escolar, através da Resolução n8, de 20 de novembro de 2012 que estabeleceu as Diretrizes Curriculares Nacionais para a Educação Escolar Quilombola na escola básica. Conforme Rodrigues “[...] Essa Diretriz ainda não é reconhecida e incorporada pelo município de Bias Fortes-MG, tanto na proposta pedagógica para a escola, quanto no Plano Decenal Municipal de Educação (PME)" (2017, p. 7).

A pesquisa de Matos (2017) analisou a influência da escola e da comunidade no processo de construção da identidade de jovens de uma comunidade de remanescentes de quilombo, o Curralinho dos Paulas, localizada na zona rural do município do Resende Costa, em Minas Gerais, no que tange a questões relacionadas às etnicidades e identidades, como também o papel da educação e das práticas educativas escolares e não escolares envolvidas nesse processo.

Após analisar tal contexto, considero que a comunidade contribui para a afirmação da identidade quilombola de seus jovens, mesmo diante das

\section{Sertanias: Revista de Ciências Humanas e Sociais - ISSN: 2763-566X Volume 1, número 1, julho-dezembro de 2020.}


desigualdades sociais e raciais que a acometem. Além das representações e imaginários que reforçam e criam estereótipos negativos, tal reconhecimento e/ou auto-atribuição se deve à ligação dos mesmos com o território de origem, a cor da pele e relações de parentesco com seus antepassados, bem como, o próprio reconhecimento cultural pela Fundação Cultural Palmares. Em relação ao contexto escolar, percebi que as práticas pedagógicas envolvendo as questões étnico-raciais e quilombolas, quando existentes, não contemplam a diversidade cultural presente dentro da escola. Dessa forma, é necessária a adoção de novas práticas e conteúdos que possam contribuir, significativamente, para a construção de identidades quilombolas positivas. Além disso, entendo que a escola, enquanto uma instituição social, ainda tem outro desafio que é contribuir, efetivamente, para o fim do ciclo de reprodução das desigualdades sociais que acomete os Paulas (MATOS, 2017, p. 8).

Lima (2019) estudou o Fórum Permanente de Educação Quilombola da Bahia, com o objetivo de compreender como se deu o processo de sua constituição e quais implicações na construção da política para educação quilombola no referido estado. O autor pontua algumas das principais demandas que incidem das comunidades quilombolas, como a implementação de políticas e de Diretrizes Curriculares para a Educação Escolar Quilombola, as relacionadas à infraestrutura, adequações nos currículos, representatividade das comunidades, metodologias de ensino, capacitação docente e acesso ao ensino superior. E então, avalia que

Assim chegamos à realização do I e II Fórum Baiano de Educação Quilombola e, concebido neles como necessidade premente, ao Fórum Permanente de Educação Quilombola da Bahia. Acreditamos que, mais que contribuições do Fórum à construção da política pública para educação quilombola no estado da Bahia, houve a enriquecedora contribuição dos movimentos sociais, das comunidades quilombolas, dos professores e professoras negros e quilombolas, dos gestores que também eram militantes do movimento negro, enfim, as pessoas negras e quilombolas que compunham o espaço dos Fóruns (LIMA, 2019, p. 133)

Macêdo (2015), em sua tese de doutorado intitulada "Educação em Comunidades Quilombolas do Território de Identidade do Velho Chico/BA: indagações acerca do diálogo entre as escolas e as comunidades locais", cujo objetivo central foi analisar de que modo a educação escolar dialoga com as especificidades étnico-culturais das comunidades quilombolas de Araçá Cariacá, Brasileira e Rio das Rãs. A autora pauta seus estudos em três escolas: a Escola Municipal Araçá Cariacá, a Escola Municipal Quilombola Emiliano Joaquim Vilaça e a Escola Municipal Elgino Nunes de Souza, ambas localizadas no município de Bom Jesus da Lapa/BA, que fazem parte do Território de Identidade do Velho Chico.

\footnotetext{
Sertanias: Revista de Ciências Humanas e Sociais - ISSN: 2763-566X Volume 1, número 1, julho-dezembro de 2020.
} 
Com o intuito de indagar se as especificidades étnico-culturais das comunidades locais são contempladas nas práticas curriculares das escolas, Macêdo (2015) afirma que as práticas curriculares das escolas pesquisadas não contemplam as especificidades étnico-culturais dos quilombolas, exceto em atividades pontuais. No entanto, ressalta algumas experiências significativas nas três escolas, de professoras que vêm transgredindo o currículo oficial no intento de encontrar outros significados para promover uma aproximação dos conteúdos escolares ao universo sociocultural dos/as alunos/as das comunidades quilombolas. No findar das suas considerações, a autora acrescenta,

Diante desse contexto, é urgente superar as propostas de educação impostas às escolas quilombolas pelo Sistema Oficial de Ensino, para elaborar propostas curriculares, interculturais, diferenciadas, referendadas pela ecologia de saberes, partindo de dentro das comunidades quilombolas, de maneira que os conteúdos escolares dialoguem com os saberes e as práticas desses sujeitos (MACÊDO, 2015, p. 185).

Souza (2015), com uma proposta de estudos semelhante a pesquisa de Macêdo, concentra-se na educação quilombola para nortear os princípios da etnopesquisa crítica. Realizou uma pesquisa de campo que se desenvolveu no quilombo Barreiro Grande, localizado no município de Serra do Ramalho/BA e, a partir da relação com os moradores, conduziu a cultura local e os saberes tradicionais para o campo da educação escolar. Sendo assim, constatou que as formas de ensinar e aprender dos quilombolas, ou seja, as pedagogias quilombolas são elementos centrais para a construção de um currículo escolar quilombola, ressaltando que a educação escolar é indissociável da realidade local e necessita estar em uma relação dialógica com a cultura, a diversidade, a identidade, os conhecimentos entre escola e comunidade, propondo o respeito as diferenças, de forma a abarcar os saberes produzidos em suas práticas sociais. Para tanto, "entendemos que a construção de um currículo escolar quilombola é possível e precisa incorporar os atos de currículo dos povos e comunidades quilombolas, desenvolvendo etnocurrículos implicados e multirreferenciados" (SOUZA, 2015, p. 8).

Silva (2020) fez uma análise do processo de recontextualização do currículo de Língua Portuguesa e Ciências proposto para uma turma multisseriada de $1^{\circ}$ e $2^{\circ}$ ano das séries iniciais do ensino fundamental, sob a ótica da prática curricular de uma professora da escola quilombola do Baixão, que se localiza no território de Vitória da Conquista-BA. O autor adentrou o contexto microssocial da instituição através da pesquisa enográfica, realizada no primeiro

\section{Sertanias: Revista de Ciências Humanas e Sociais - ISSN: 2763-566X Volume 1, número 1, julho-dezembro de 2020.}


semestre 2019. A análise dos dados coletados, através de entrevistas e observação, ancorou-se no referencial teórico de Barnstein (1996), a partir do conceito de recontextualização de regras e práticas.

Silva (2020) apresenta alguns achados da pesquisa, que nos auxiliam a pensar como a maneira de ensinar e aprender têm se configurado nos diferentes contextos da educação escolar quilombola.

Sobre a escola estar situada numa comunidade quilombola, percebeu-se uma prática distante do que está proposto nas Diretrizes Curriculares Nacionais para a Educação Escolar Quilombola, uma vez que a docente não trabalha com materiais específicos e, além disso, aborda a realidade sociocultural das crianças de forma incipiente. Desse modo, verificou-se o predomínio de uma pedagogia visível, isto é, aquela que se relaciona com o código elaborado, compreendido também como currículo de coleção. Há indícios, entretanto, de uma pedagogia invisível, visto que a disciplina de Língua Portuguesa apresenta currículo de integração, na medida em que ocorre diálogo no trabalho com as demais disciplinas, ou seja, há permeabilidade entre as áreas do conhecimento, como tangencia Bernstein (1996) (SILVA, 2020, p. 91).

A pesquisa de Matos (2017), com o tema "Etnicidade, educação e reconhecimento de si entre as crianças quilombolas da comunidade Nova Esperança", contribui de maneira significativa com as propostas de se pensar a educação escolar quilombola no contexto da implementação das políticas para essa modalidade de ensino, quando questiona,

De que forma se configura o processo de construção do ser quilombola entre os moradores da comunidade quilombola de Nova Esperança e como as práticas educativas desenvolvidas na Escola Quilombola Caminho da Boa Esperança têm contribuído para o reconhecimento das crianças enquanto quilombolas? (MATOS, 2017, p. 8).

Nesse sentido, investiga as relações étnicas e o reconhecimento entre os quilombolas da Comunidade Nova Esperança, alicerçado na Teoria Crítica de Axel Honneth, para pensar o reconhecimento intersubjetivo das crianças e dos adultos da comunidade e no modelo quadripartido 4 formulado por José Maurício Arruti. O autor coloca em evidência as concepções que as crianças e os adultos constroem acerca do ser quilombola e como a escola tem inserido

\footnotetext{
4 "Um modelo de análise chamado de "processo de formação quilombola", modelo que é quadripartido em nominação, identificação, reconhecimento e territorialização” (ARRUTI, 2006, p. 45).
}

\section{Sertanias: Revista de Ciências Humanas e Sociais - ISSN: 2763-566X Volume 1, número 1, julho-dezembro de 2020.}


as questões quilombolas em seu currículo e que tipo de escola a comunidade quer para seus filhos e para Nova Esperança. Nesse sentido, segundo Matos,

Quando Beija-flor nos diz que ser quilombola é uma pessoa bem falada na comunidade, nos parece que enquanto grupo, os quilombolas de Nova Esperança teria atingido a auto-estima correspondente ao terceiro estágio de reconhecimento elaborado por Honneth, aquele que corresponde à auto-estima interna do grupo, sendo assim, "a estima social se coloca a questão de como se constitui o sistema referencial valorativo no interior do qual se pode medir o "valor" das propriedades características (HONNETH, 2003, p. 187) (MATOS, 2017, p. 107).

No centro do debate sobre as conquistas alcançadas pelas comunidades quilombolas em busca de seus direitos por educação, Cordeiro (2017) conduz uma importante discussãocentrada no questionamento de como os quilombolas situam a educação pública frente à conquista de seus direitos. Afirma que "a principal hipótese é que os quilombolas situam a educação escolar pública como necessária para fazer realizar direitos fundamentais, considerando uma constante na vivência e na luta política de suas comunidades" (CORDEIRO,2017, p. 9). Contudo, o autor destaca que muitas vezes as escolas quilombolas possuem características comuns às escolas de outras regiões, ou seja, não assumem as especificidades necessárias para atender os anseios das comunidades onde se inserem. Contudo, defende que as Diretrizes para a educação escolar quilombola representam uma grande conquista, mas pondera que ainda requer estratégias e maneiras de utilizá-las em prol da conquista de escolas que contemplem as particularidades das comunidades quilombolas, suas formas de apreender, de conviver e produzir conhecimento.

A pesquisa de Silva (2017) objetivou compreender os "referenciais epistêmicos que orientam e substanciam práticas curriculares em uma escola localizada na comunidade quilombola de Conceição das Crioulas”, tendo como referencial teórico-metodológico o pensamento afrocêntrico, apresentado por Assante (2009), Ki-Zerbo (2011) e a perspectiva decolonial latino americano, tendo por interlocutores Dussel (2010), Quijano (2005), Mignolo (2005, 2008), Maldonado-Torres (2007), Escobar (2005), Grosfoguel (2013, 2010, 2017) e Walsh $(2005,2009,2010)$.

Conforme Silva, a escola estudada tem implementado, em seu Projeto Político Pedagógico, “as questões sócio históricas e culturais da Educação Quilombola, apresentando, assim, uma educação que considera a história e realidade da comunidade escolar, e caminha

\footnotetext{
Sertanias: Revista de Ciências Humanas e Sociais - ISSN: 2763-566X Volume 1, número 1, julho-dezembro de 2020.
} 
para uma efetivação destas políticas educacionais no chão da escola" (SILVA, 2017, p. 13). Ademais, segundo a autora,

Os resultados da pesquisa indicam que a consciência e organização política dos quilombolas possibilitaram a conquista da educação específica dialogada com as Bases da Educação Nacional. A formação inicial de professores responde incipientemente às necessidades da qualificação do professor quilombola. É a formação continuada, conduzida pela gestão escolar junto com professores e comunidade que tem cumprido com a função social da escola no sentido de proporcionar emancipação e identificação de estudantes e suas famílias com a escola e com o seu pertencimento identitário; as práticas curriculares desenvolvidas estão centradas na História e Cultura Afrobrasileira, referenciada na tradição oral, história e memória, considerando os quilombos como uma experiência continental da Diáspora africana (SILVA, 2017, p. 13 e 14).

Fazendo uma análise da Educação Quilombista ${ }^{5}$, como proposta de uma educação afrocentrada no Brasil, Benedicto (2019) defende que somente uma educação centrada e dos afro-brasileiros (o que define como sistema de ensino quilombista) será determinante para viabilizar a formação que os africanos da diáspora no Brasil necessitam, tornando, assim, “de modo adequado as leis 10.639/03 e 11.645/08 bem como as Diretrizes Curriculares de 2004 para o ensino de História e Cultura Afro-Brasileira e Africana” (BENEDICTO, 2019, p. 18). Segundo o autor, “o desenvolvimento da Educação Quilombista se impõe, pois vivemos em uma sociedade orientada pelos princípios do eurocentrismo e da supremacia branca" (BENEDICTO, 2019, p. 18).

Campos e Souza (2015) refletiram sobre a necessidade de diálogo entre o campo dos estudos decoloniais e a educação escolar quilombola. Os autores tecem reflexões acerca do quilombo e da educação escolar quilombola sob o olhar da pedagogia decolonial/intercultural. Para o desenvolvimento das discussões, apresentam considerações sobre a constituição histórica do movimento quilombola, além do debate sobre o projeto

\footnotetext{
${ }^{5} \mathrm{O}$ autor define a Educação Quilombista como, “[...] um processo de transmissão dos valores, crenças, costumes e conhecimentos para que os afro-brasileiros possam viver de maneira adequada nesta sociedade garantindo, assim, a continuidade do seu povo e de sua cultura. Esta educação deve ser inspirada na experiência dos quilombos, visto que estas sociedades permitiram aos africanos existirem nesta terra sem renunciarem a sua africanidade, além de serem abertas aos indígenas e brancos excluídos do sistema colonial. Assim como os quilombos se constituíram como espaços de construção da identidade afro-brasileira e de resistência à aculturação europeia a educação quilombista, hoje, deve ser concebida como um processo de formação do amefricano do Brasil e de resistência ao historicamente constituído modelo eugênico e eurocêntrico de educação com vistas à construção da sociedade democrática intercultural quilombista (BENEDICTO, 2019, p. 245).
}

\author{
Sertanias: Revista de Ciências Humanas e Sociais - ISSN: 2763-566X \\ Volume 1, número 1, julho-dezembro de 2020.
}


modernidade/colonialidade, tendo em vista que se mantêm "presente e atuante o controle econômico, político e epistemológico de determinadas culturas sobre outras "(CAMPOS; SOUZA, 2015, p. 37313)”.

Além disso, os autores identificam que o movimento quilombola carrega uma luta histórica de resistência contra a colonialidade. Uma luta na qual os impasses se revelam no campo educacional, quando afirmam as contribuições para a história e cultura na produção de seus saberes. "O diálogo entre o projeto decolonial e os sujeitos quilombolas propõe o combate a subalternização, na medida em que desoculta a colonialidade e legitima as suas produções culturais" (CAMPOS; SOUZA, 2015, p. 37314). Com isso, os autores defendem que adotar práticas educativas quilombolas, nas perspectivas pedagógicas decoloniais/interculturais, é assumir uma pedagogia que se incube de descentralizar a cultura, reavendo saberes e práticas das diversas populações que constituem a sociedade brasileira.

Paula e Nazário (2017) apresentam reflexões sobre as incursões feitas durantes seus estudos, que dizem respeito "ao lugar ou não-lugar, como diz Auge (1994), atribuído às crianças quilombolas no âmbito da legislação brasileira, fazendo referência às leis que tratam da educação nacional" (PAULA; NAZÁRIO 2017, p. 96). As autoras contribuem de maneira significativa para compreendermos as relações educativas e o lugar ocupado pelas crianças de quatro a seis anos de idade nas duas comunidades estudadas. Segundo as autoras,

Nas escolas frequentadas pelas crianças provenientes das comunidades quilombolas não se estabelecia uma articulação entre os saberes da instituição escolar e aqueles trazidos pelas crianças, tais como as formas de captação da agua no quilombo, o não desperdício de água e de alimentos, a irrigação da horta, a colheita do café, o corte de banana, o cuidado com os animais, a utilização de ervas medicinais, dentre outros saberes e experiências presentes nas comunidades (PAULA; NAZÁRIO 2017, p. 107)

Iniciemos, pois, por admitir nosso grande "desconhecimento" sobre as crianças quilombolas e abraçar a hipótese de que toda tentativa de as enquadrar em uma normatização com referências fixas e unidirecionais aniquila sua capacidade criativa e impede nossa possibilidade de enxergar outras formas de pensar sobre os mundos infantis e sobre as infâncias. Compreendemos que as formas de expressão ou de sociabilidade nos contextos em que vivem podem suscitar outras maneiras de refletir sobre as relações educativas em contextos institucionalizados, por exemplo. Devemos, pois, assumir nossas incertezas e nos posicionar na perspectiva de diálogo aberto com as diversas realidades vividas pelas diferentes crianças. A

\section{Sertanias: Revista de Ciências Humanas e Sociais - ISSN: 2763-566X Volume 1, número 1, julho-dezembro de 2020.}


efetivação da legislação educacional já existente pode muito bem auxiliar nesse mister! (PAULA; NAZÁRIO 2017, p. 109).

Por fim, queremos destacar a pesquisa de Santos (2015) que se constituiu em uma etnografia sobre as aprendizagens das crianças da comunidade quilombola do Arrojado, localizada no Rio Grande do Norte, tendo a Escola Municipal Manoel Joaquim de Sá -EMMJS, localizada na zona rural do município de Portalegre/RN, como campo empírico. Trata-se, portanto, de uma escola não quilombola que atende a estudantes vindos de uma comunidade remanescente de quilombo. A etnografia buscou destacar o percurso dos alunos da comunidade à sua chegada à escola, destacando o cotidiano, a identidade e a convivência desses estudantes em ambos os espaços. A pesquisa possibilita uma reflexão sobre a relação do ensino entre os alunos do Arrojado e a EMMJS, pensando esses sujeitos a partir da construção da identidade coletiva quilombola e a questão da auto atribuição que os categorizam como sendo "os morenos", cujo intuito é compreender, dentro do contexto da escola, os problemas enfrentados em virtude do racismo e da discriminação. Conforme Santos,

[...] as práticas pedagógicas desenvolvidas na escola apontam para uma não relação de aprendizagem com aquilo que é transmitido pela comunidade quilombola por meio do seu cotidiano, tradição e cultura, se contrapondo com o que preleciona a Lei $\mathrm{n}^{\circ}$. 10.639/2003, que estabelece as diretrizes e bases da educação nacional, e determina a inclusão no currículo oficial da rede de ensino, a obrigatoriedade da temática "História e Cultura Afro-Brasileira" (2015, p. 10).

A autora afirma que o preconceito racial e a discriminação na escola estudada têm assumido um espaço de intolerância. "Professores têm silenciado sua prática, contribuindo para o desrespeito e desprezo à cultura, à identidade e à tradição dos moradores da Comunidade do Arrojado, além de provocar, em alguns alunos, o desinteresse para o ensino formal” (SANTOS, 2015, p. 28). Ademais, "os alunos quilombolas são afetados no cotidiano e no seu desenvolvimento cognitivo pelas diversas formas de violência racial presentes no contexto escolar" (SANTOS, 2015, p. 29).

Foram inúmeras as vezes que ouvi professores fazerem menção aos alunos quilombolas como sendo "descompromissados com a escola" e que apresentavam "dificuldade de aprendizagem" ou ainda relatos do tipo "eu não sei o que acontece, mas eles não aprendem", e "eles não estão nem aí". Partes dessas afirmações foram ditas em sala de aula no procedimento de mediação dos conteúdos. [...] As denominações impetradas aos alunos do Arrojado são, 
em sua maioria, assinaladas como sendo: "desinteressados", "aprendizagem lenta", "dificuldade", "grande carência em parte do aprendizado" e "pouco se destaca" (SANTOS, 2015, p. 67-75).

Na escola Manoel Joaquim de Sá, apresentam-se inúmeras dificuldades no que diz respeito à discriminação dos alunos negros oriundos da comunidade quilombola, práticas essas não muito visualizadas pela equipe escolar, tais como xingamentos, recusa de fazer atividades com os alunos quilombolas que, por vezes, são negadas e/ou silenciadas. "Na escola pesquisada o racismo tem se expressado de diversas maneiras, como a negação da cultura e da tradição africana e afrodescendente, dos costumes, através das práticas de xingamentos, dentre outras maneiras" (SANTOS, 2015, p. 86).

Na escola Municipal Manoel Joaquim de Sá, os discursos e os olhares que recaem sobre os alunos do Arrojado partem da ideia de que eles são diferentes. Diferentes na forma de aprender, de se comportar e de se relacionar com os demais colegas. Além disso, para alguns alunos essa diferença se dá em virtude da cor, dificultando a aceitação das características físicas e corporais, afastando-os de outros grupos e sujeitos. Por conseguinte, acentua-se a não aceitação dos quilombolas no cotidiano escolar provocando distanciamento e rejeição (SANTOS, 2015, p. 155).

\section{Considerações finais}

Segundo Gusmão e Souza (2012), pensar a educação quilombola, seja em escolas quilombolas ou em escolas que recebem estudantes quilombolas, como a apresentada por Santos (2015), Macedo (2019) e a escola foco de nossa pesquisa, implica em construir uma escola para a diversidade, "em que professores e gestores tivessem em sua formação condições para o trabalho pedagógico com toda e qualquer expressão de diversidade cultural" (GUSMÃO; SOUZA, 2012, p. 242-243). Implica, como temos defendido em nossa pesquisa, construir uma perspectiva de educação firmada nos princípios da "interculturalidade crítica" (WALSH, 2009), antirracista, capaz de produzir justiça cognitiva e epistêmica, como propõe Boaventura de Souza Santos (2019), em diálogo com diferentes regimes de conhecimentos, a exemplo dos elaborados pelas comunidades remanescentes de quilombos. Na perspectiva de BernardinoCosta, "o epistemicídio não ocorre somente em escola global, mas possui também suasvertentes nacionais, que se efetivam por meio do silenciamento e de desprezo de outras narrativas e de outros conhecimentos, como por exemplo, uma narrativa epistemologicamente negra ou indígena" (2015, p. 2015, p. 39).

\section{Sertanias: Revista de Ciências Humanas e Sociais - ISSN: 2763-566X Volume 1, número 1, julho-dezembro de 2020.}


Como vimos, nas pesquisas aqui apresentadas, muitas das escolas, inclusive em territórios quilombolas, estão prenhes de práticas epistemicidas, racistas e monoculturais, posto que continuam estruturadas na lógica do "pensamento abissal". Contudo, os coletivos negros e quilombolas estão empenhados na produção de "ecologias dos saberes" (SANTOS, 2006), sejam nos espaços escolares ou fora dele, mesmo a despeito das muitas dificuldades que enfrentam. No caso dos espaços escolares, uma "educação intercultural deve produzir justiça cultural”, como propõe Méndez (2009), uma vez que, conforme este autor, ler e escrever, assim como outras destrezas e conhecimentos impulsionados a partir dos ambientes escolares - "a linguagem, a memória coletiva, a experiência de encontro com "outros" diversos, a arte, a religião, a aprendizagem dos idiomas - podem converter-se em ferramentas importantes para a demanda por justiça cultural” (2009, p. 62). Nesse sentido, segundo Santiago, Akkari e Marques (2013, p. 21), “como projeto político e social, a interculturalidade crítica exige uma pedagogia que afirme a diferença em seus aspectos histórico-político-sociais e de poder”. Acreditamos que, mesmo diante das contradições e desigualdades que atravessam o chão da escola e tendo em vista algumas das experiência apresentadas neste capítulo, é possível superar essas situações e produzir outras pedagogias e experiências escolares capazes de transformar "a colonialidade do poder, do saber e do ser” (MALDONADO-TORRES, 2019). Isso só será possível se recolocarmos os coletivos negros, quilombolas, indígenas, etc., como protagonistas na construção de seus projetos de presente e de futuro que, há muito tempo, têm construído movimentos decoloniais.

\section{REFERÊNCIAS}

BENEDICTO, Ricardo Matheus. Educação quilombista: uma proposta de educação afrocentrada no Brasil. Revista Sul-Americana de Filosofia e Educação. Número 31: mai.out./2019, p. 18-33.Disponível em: https://doi.org/10.26512/resafe.vi30.28254. Acesso em: 10 de Out. de 2020

BERNARDINO-COSTA, Joaze. Saberes subalternos e decolonialidade: os sindicatos das trabalhadoras domésticas no Brasil. Brasília: EdUnB, 2015.

BRASIL. Diretrizes Curriculares Nacionais para a Educação das Relações ÉtnicoRaciais e para o Ensino de História e Cultura Afro-Brasileira e Africana. Brasília: Ministério da Educação, 2004. 
BRASIL. Presidência da República Casa Civil. Subchefia para assuntos jurídicos. Decreto n. ${ }^{\circ}$ 6040 de 7 de fevereiro de 2007, Institui a Política Nacional de Desenvolvimento Sustentável dos Povos e Comunidades Tradicionais. DF, 2007. Disponível em:

http://www.planalto.gov.br/ccivil_03/_ato2007-2010/2007/decreto/d6040.htm. Acesso em: 06 de nov. 2020

BRASIL. Presidência da República Casa Civil. Subchefia para assuntos jurídicos. Lei 10.639 de 09 de janeiro de 2003. Altera a Lei no 9.394, de 20 de dezembro de 1996, que estabelece as diretrizes e bases da educação nacional, para incluir no currículo oficial da Rede de Ensino a obrigatoriedade da temática "História e Cultura Afro-Brasileira", e dá outras providências. Disponível em: http://www.planalto.gov.br/ccivil_03/leis/2003/110.639.htm. Acesso em: 20 novembro de 2020.

BRASIL. Ministério da Educação, Conselho Nacional de Educação, Câmara de Educação Básica. CNE/CP 003/2004, aprovado em 10/03/2004. Parecer das Diretrizes Curriculares Nacionais para a Educação das Relações Étnico-Raciais e para o Ensino de História e Cultura Afro-Brasileira e Africana. Brasília, DF, 2004a.

BRASIL. Ministério da Educação, Conselho Nacional de Educação. RESOLUÇÃ̃ No 1 , DE 17 DE JUNHO DE 2004, que institui Diretrizes Curriculares Nacionais para a Educação das Relações Étnico- Raciais e para o Ensino de História e Cultura Afro-Brasileira e Africana. Brasília, DF, 2004b.

BRASIL. Ministério da Educação, Conselho Nacional de Educação, Câmara de Educação Básica. Diretrizes Curriculares Gerais para a Educação Básica. Parecer CNE/CEB no 7/2010. Brasília, Conselho Nacional de Educação, 2010.

BRASIL. Ministério da Educação, Conselho Nacional de Educação, Câmara de Educação Básica. Parecer homologado CNE/CEB, 16/12 do Conselho Nacional de Educação/Câmara de Educação Básica, publicado no D.O.U. de 20/11/2012, Seção 1, Pág. 8, que institui as Diretrizes Curriculares Nacionais para a Educação Escolar Quilombola. Brasília, DF, 2012a.

BRASIL. Ministério da Educação, Conselho Nacional de Educação, Câmara de Educação Básica, Resolução n⿳0 8, de 20 de novembro de 2012, que define as Diretrizes Curriculares Nacionais para a Educação Escolar Quilombola na Educação Básica, Brasília, DF, 2012b.

CANDAU, Vera Maria. (Org.) Somos tod@s iguais? Escola, discriminação e educação em direitos humanos. Rio de Janeiro: DP\&A, 2003.

CAMPOS, Louise Rodrigues; SOUZA, Sulivan Ferreira de. Educação quilombola e decolonialidade: um diálogo intercultural. Anais do EDUCERE XII Congresso Nacional de Educação, 2015. 
CAMPOS, Margarida Cássia; GALLINARI, Tainara Sussai. A educação escolar quilombola e as escolas quilombolas no Brasil. Revista Nera, Ano 20, n. 35, pp. 199-217, janeiro/abril de 2017 - ISSN: 1806-6755.

CORDEIRO, Mauro Soares. Política Educacional e conquista de direitos: escolas públicas em comunidades quilombolas. 2017. 226 p. Tese (Doutorado)- Faculdade de Educação da Universidade de São Paulo, Programa de Pós-Graduação em Educação. Área de concentração: Educação e Ciências Sociais, São Paulo, 2017.

FRANCO, Lara Luisa Silva Gomes, Educação quilombola, resistência e empoderamento : estudo na comunidade quilombola de são domingos em Paracatu-MG. 2018. $133 \mathrm{f}$. Dissertação (Mestrado em Educação) - Universidade Federal de Uberlândia, Uberlandia, 2018.

GOMES, Nilma Lino. O movimento Negro Educador: saberes construídos nas lutas por emancipação. Petrópolis, RJ: vozes, 2017.

GOMES, Nilma Lino (org.) Práticas pedagógicas de trabalho com relações étnico-raciais na escola na perspectiva da Lei 10.639/03. 1 ed. Brasília: MEC; Unesco, 2012. Disponível em: http://ciclopermanenteufmg.com.br/wp-content/uploads/2018/07/Pr\%C3\%A1ticasPedag\%C3\%B3gicas-de-Trabalho-com-a-Lei-10.639_03.pdf. Acesso em: 10 de ago. de 2020.

GUSMÃO, Neuza Maria Mendes de. Antropologia e Educação Quilombola: etinicidade e mediação. EntreRios Revista do PPGANT-UFPI, v. 3, n.1 p. 9-26, 2020. Disponível em: https://revistas.ufpi.br/index.php/entrerios/article/view/11628. Acesso em: 06 de Out. de 2020.

GUSMÃO, Neusa M.M.; SOUZA, Márcia Lúcia A. "Educação Quilombola entre saberes e lutas".In: DAUSTER, Tania; TOSTA, Sandra P.; ROCHA, Gilmar (orgs.) Etnografia e educação. Rio de Janeiro: Lamparina, 2012, pp. 222- 245.

LIMA, Aderaldo Santos de. Fórum permanente de educação quilombola da Bahia: uma análise do processo participativo de construção e monitoramento da política pública para Educação Quilombola. Dissertação (Mestrado Acadêmico) - Universidade do Estado da Bahia. Departamento de Educação. Programa de Pós-Graduação em Educação e Contemporaneidade - PPGEDUC, Campus I, Salvador, 2019.

MACÊDO, Dinalva de Jesus Santana. Educação em Comunidades Quilombolas do Território de Identidade do Velho Chico/BA: indagações acerca do diálogo entre as escolas e as comunidades locais. 2015. 216 f. Tese (Doutorado em Educação) - Faculdade de educação, Universidade do Estado da Bahia, Salvador, 2015.

MACEDO, Liliane de Fátima Dias. A implementação das diretrizes curriculares nacionais para a educação escolar quilombola na educação básica em escolas da comunidade de Quartel do Idaiá/MG. 180 f. Dissertação (Mestrado)- Universidade Federal de Ouro Preto, Instituto de Ciências Humanas e Sociais, Departamento de Educação, Programa de Pósgraduação em Educação. Mariana, 2019.

Sertanias: Revista de Ciências Humanas e Sociais - ISSN: 2763-566X Volume 1, número 1, julho-dezembro de 2020. 
MACEDO, Liliane de Fátima Dias; SANTOS, Erisvaldo Pereira dos. Estado da arte das pesquisas sobre Educação Escolar Quilombola nos Programas de Pós-graduação em Educação no Brasil. Anais do X Congresso Brasileiro de Pesquisadores Negros- COPENE, Uberlândia, 2018. Disponível em: https://www.copene2018.eventos.dype.com.br/resources/anais/8/1536859363_ARQUIVO_LI LIANEMACEDO-TEXTOCOMPLETOCOPENE.pdf. Acesso em: 27 de out. 2020.

MALDONADO-TORRES, Nelson. Analítica da colonialidade e da decolonialidade: algumas dimensões básicas. In: BERNADINO-COSTA, J.; MALDONADO-TORRES, N.; GROSFOGUEL,R. (Orgs.). Decolonialidade e pensamento afrodiaspórico. 2 ed. 1 reim. Belo Horizonte: Autêntica, 2019, p. 27-53.

MATOS, Diogo Pereira. Quilombo, escola e identidades: um estudo sobre a comunidade remanescente de quilombo do Curralinho dos Paulas do Município de Resende Costa/MG. 196 f. Dissertação (Mestrado em Processos Socioeducativos e Práticas Escolares) Universidade Federal de São João del-Rei, São João del-Rei, 2017.

MATOS, Wesley Santos de. "Etnicidade, educação e reconhecimento de si entre as crianças quilombolas da comunidade nova esperança". 2017. 138 f. Dissertação (Mestrado em Relações Étnicas Raciais e Contemporaneidades) - Universidade do Estado da BahiaUESB, Jequié, 2017.

MÉNDEZ, José Mario Méndez. Educação intercultural e justiça cultural. Traduzido por Antonio Sidekum. São Leopoldo: Nova Harmonia, 2009

NASCIMENTO, Abdias do. O genocídio do negro brasileiro: Processos de um racismo mascarado. 3 ed. São Paulo: Perspectivas, 20016. p. 232.

PAULA, Elaine de; NAZÁRIO Roseli. Entre o quilombo e a educação infantil: o (não) lugar das crianças quilombolas na política educacional brasileira. P O I É S I S - Revista do programa de pós-graduação em educação - mestrado - Universidade do Sul de Santa Catarina-Unisul. Tubarão, v.11, n. 19, p. 96 - 111, Jan/Jun 2017. Disponível em: http://dx.doi.org/10.19177/prppge.v11e19201796-111. Acesso em: 20 de Out. 2020.

RODRIGUES, Guilherme Goretti. A Educação Quilombola na Comunidade Colônia do Paiol - Bias Fortes (MG). 111 f. Dissertação (mestrado acadêmico) - Universidade Federal de Juiz de Fora, Faculdade de Educação, Juiz de Fora, 2017.

SANTANA, José Valdir J; EUGÊNIO, Benedito G; OLIVEIRA, NAKSON W.S.; PEREIRA, Claudia de J. "A Educação Escolar Quilombola na ANPED: análise da produção do GT. 21 Educação e Relações Étnico-Raciais”. ACENO, 3(6), ago - Dez 2016: 137-158. Disponível em:http://periodicoscienti $\square$ cos.ufmt.br/ojs/index.php/aceno/article/view/4333/pdf. Acesso em: 02/11/2020.

SANTIAGO, Mylene Cristina; AKKARI, Abdeljalil; MARQUES, Luciana Pacheco. Educação Intercultural: desafios e possibilidades. Petrópolis (RJ): Vozes, 2013.

Sertanias: Revista de Ciências Humanas e Sociais - ISSN: 2763-566X Volume 1, número 1, julho-dezembro de 2020. 
SANTOS, Boaventura de Souza. A gramática do tempo: para uma nova cultura política. São Paulo: Cortez, 2006.

SANTOS, Boaventura de Souza. O fim do império cognitivo: A afirmação das epistemologias do Sul. Belo Horizonte: Autêntica, 2019. 480 p.

SANTOS, Maria do Socorro dos. Cotidiano e aprendizagens de alunos quilombolas do Arrojado - Porto Alegre/RN. 174 f. Dissertação (Mestrado em Ciências Sociais e Humanas) - Universidade do Estado do Rio Grande do Norte, Mossoró,2015.

SILVA, Delma Josefa da. Referenciais Epistêmicos que Orientam e Substanciam Práticas Curriculares em uma Escola localizada na Comunidade Quilombola de Conceição das Crioulas. 236 f. Tese (Doutorado) - Universidade Federal de Pernambuco, Programa de Pósgraduação em Educação, Recife, 2017.

SILVA, Elenilson Evangelista da. A recontextualização do currículo nos anos iniciais do ensino fundamental: etnografia em uma escola quilombola de Vitória da Conquista - Ba. 122 f. Dissertação (Mestrado em Ensino) - Universidade Estadual do Sudoeste da Bahia, Vitória da Conquista, 2020.

SOUZA, Elizabete das Dôres Gomes de. A comunidade dos Arturos, os desafios e as perspectivas para a educação quilombola: diálogos entre educação, gestão social e desenvolvimento local. 126 f. Dissertação (Mestrado) - Centro Universitário UMA, Programa de pós-graduação em Gestão Social, Educação e Desenvolvimento Local, Belo Horizonte, 2018.

SOUZA, Shirley Pimentel de. Educação escolar quilombola: as pedagogias quilombolas na construção curricular. 2015. 111 f. Dissertação (Mestrado Em Educação) - Universidade Federal da Bahia, Faculdade de Educação, Programa de Pós-Graduação em Educação.

Salvador, 2015.

WALSH, Catherine. Interculturalidade crítica e pedagogia decolonial: in-surgir, re-existir e re-viver. In: CANDAU, Vera Maria (Org.). Educação intercultural na América Latina: entre concepções, tensões e propostas. Rio de Janeiro: 7Letras, 2009. 